University of South Carolina

Scholar Commons

6-2013

\title{
Path Loss in an Urban Peer-to-Peer Channel for Six Public-Safety Frequency Bands
}

\author{
David W. Matolak \\ University of South Carolina - Columbia, matolak@cec.sc.edu \\ Qian Zhang \\ Qiong Wu
}

Follow this and additional works at: https://scholarcommons.sc.edu/elct_facpub

Part of the Digital Communications and Networking Commons, Signal Processing Commons, and the Systems and Communications Commons

\section{Publication Info}

Postprint version. Published in IEEE Wireless Communications Letters, Volume 2, Issue 3, 2013, pages 263-266.

(C) IEEE Wireless Communications Letters, 2013, IEEE Matolak, D., Zhang, Q., Wu, Q. (2013). Path Loss in an Urban Peer-to-Peer Channel for Six Public-Safety Frequency Bands, IEEE Wireless Communications Letters, 2(3), 263-266.

http://dx.doi.org/10.1109/WCL.2013.020513.120919

This Article is brought to you by the Electrical Engineering, Department of at Scholar Commons. It has been accepted for inclusion in Faculty Publications by an authorized administrator of Scholar Commons. For more information, please contact digres@mailbox.sc.edu. 


\title{
Path Loss in an Urban Peer-to-Peer Channel for Six Public-Safety Frequency Bands
}

\author{
David W. Matolak, Senior Member, IEEE, Qian Zhang, and Qiong Wu
}

\begin{abstract}
We provide path loss data and models for a peerto-peer wireless channel for an urban environment in six public safety bands, for simultaneous transmission to five spatially separated receiving sites. Results are from measurements in Denver, Colorado. The six frequencies at which we measured are (in MHz) 430, 750, 905, 1834, 2400, and 4860. Both lineof-sight and non-line-of-sight conditions were covered, and we quantify path loss exponents and linear-fit standard deviations as functions of frequency and location. Line-of-sight results agree with prior work, but non-line-of-sight exponents, from 3.6-7.3, are generally larger than in most other references.
\end{abstract}

Index Terms-Propagation, channel characterization and modeling

\section{INTRODUCTION}

$\mathbf{I}$ NCREASED attention has been given to public safety communications in recent years [1]. For response to either natural or human-made emergencies, public safety personnel require reliable communications for "emergency responders" during and after emergency events. Design of a reliable communication system requires a good knowledge of the propagation environment, and this includes a good model for propagation path loss, the subject of this paper.

In the USA, two former television broadcast bands at 764$776 \mathrm{MHz}$ and $794-806 \mathrm{MHz}$ have been re-allocated to public safety. A $50 \mathrm{MHz}$ band from $4940-4990 \mathrm{MHz}$ has also been allocated.

Past public-safety communication systems often used a "single cell" for "dispatch" purposes. Those systems connected a mobile user to a single elevated base station that covered a wide area. New deployments-particularly the incident area network (IAN) - are in the process of development [1]. The IAN can operate as an ad hoc network, temporarily deployed to provide communication services for emergency responders during and after an emergency event. IAN environments of interest include urban settings, both indoor and outdoor, and between. In such settings, base stations will not have elevated antennas, so communications are ground-based, or "peer-to-peer" (P2P), with all units employing low-elevation antennas.

Ad hoc networks are seeing a great deal of attention in general. References [2]-[6] represent a small sample of the literature on a variety of characteristics of these networks.

Manuscript received December 14, 2012. The associate editor coordinating the review of this letter and approving it for publication was I. Guvenc.

D. Matolak is with the Department of Electrical Engineering, University of South Carolina, Columbia, SC, 29208 USA (e-mail: matolak@sc.edu).

Q. Zhang is with InterDigital Corp., 781 Third Avenue, King of Prussia, PA 19406 USA.

Q. Wu is with Apple, Inc., 1 Infinite Loop, Cupertino, CA 95014 USA.

Digital Object Identifier 10.1109/WCL.2013.020513.120919
Topics of study include routing [2] and capacity [3], crosslayer design [4], physical layer issues related to these topics [5], and multiple access, duplexing, and multiplexing [6]. Few authors address the issue of inter-node propagation, and when they do, they typically assume uniform large-scale propagation conditions over the network area [7], [8]. Reference [9] is one of the few we have found that relaxes this ideal propagation assumption, and as we will show, this uniformity of propagation conditions is not borne out by experiment.

It is well known that wireless channels have been characterized for many environments and in multiple frequency bands, with the cellular setting seeing the most attention, e.g., [10]. Indoor channels have also seen much attention [11], and newer, atypical channels such as vehicle-to-vehicle [12] have been measured and modeled, whereas ground-based (or P2P) channels have seen far less attention. Urban path loss for P2P conditions in the ultra-high-frequency (UHF) band was reported in [13]. Our recent work [14] modeled P2P path loss for a single urban street, and also provided new tapped delay line channel models (based upon wideband measurements) for the $700 \mathrm{MHz}$ and $4900 \mathrm{MHz}$ public-safety bands. Microcell channels have been thoroughly studied by standards bodies, but these usually focus on antenna heights of 3-4 m, in contrast to the pedestrian-height $(1.6 \mathrm{~m})$ antennas we employ here.

Despite the rich literature, few references report on characteristics of simultaneous propagation to multiple sites, or on propagation of multiple frequencies spanning a very wide frequency range. This work addresses this gap: we measured the power received at five receivers, simultaneously, in an urban environment, with transmission from a single mobile pedestrian transmitter. This was done for six continuous wave (CW) frequencies in or very near to current public-safety bands, spanning over a decade in frequency: $430 \mathrm{MHz}, 750$ MHz, $905 \mathrm{MHz}, 1834 \mathrm{MHz}, 2400 \mathrm{MHz}$, and $4860 \mathrm{MHz}$. To our knowledge, this frequency span is the widest for which results have been reported. From these results, we compute statistics on path loss in the urban P2P environment.

The rest of this paper is organized as follows: Section II describes the urban environment and measurements. Section III presents results and models for path loss in P2P urban lineof-sight (LOS) and non-LOS (NLOS) conditions. Section IV is the conclusion.

\section{Measurement Description}

Measurements were taken outdoors in downtown Denver, CO, in the financial district on Saturday, July 18, 2009. This area contains many large (over 20-story) buildings. Figure 1 illustrates the test area, drawn using a Google map view. ${ }^{1}$

\footnotetext{
${ }^{1}$ (C) 2010 Google, Map Data (c) 2010 Tele Atlas.
} 
The area was approximately bounded by California Street and Tremont Place, and by the $16^{\text {th }}$ Street Mall and $18^{\text {th }}$ Street. The numbers (1-24) in Fig. 1 denote consecutive transmitter locations, and the circles denoted $R i, i \in\{1,2,3,4,5\}$ indicate the five stationary receiver locations. Each frequency was measured with the two-person transmit team walking the numbered path at pedestrian velocities $(=5 \mathrm{~km} / \mathrm{h}=1.4 \mathrm{~m} / \mathrm{s})$, stopping at corners (Fig. 2). The additional data taken while stopped improves the averages for the highest frequencies at these points ${ }^{2}$. All relevant distances were measured. The receivers collected data continuously during each walk, with power sampled at approximately 2 samples/second. Since we are not concerned with small-scale multipath fading, and do additional averaging in post-processing to average this out, this sampling rate is sufficient for assessing the large-scale effects.

Transmitters sent CW signals [15]. Power levels were 1 watt for the four lowest frequencies $(430 \mathrm{MHz}, 750 \mathrm{MHz}$, $905 \mathrm{MHz}, 1834 \mathrm{MHz}$ ), and 2 watts for the 2400 and 4860 $\mathrm{MHz}$ frequencies. Transmitter antennas were quarter-wave monopoles. Spectrum analyzers were used as the receivers. Each receiver employed wideband omnidirectional (azimuth) antennas: discones of bandwidth $300 \mathrm{MHz}-1 \mathrm{GHz}$ for the lower three frequencies, and conical monopoles of bandwidth $1 \mathrm{GHz}-18 \mathrm{GHz}$ for the upper three frequencies. Antenna heights were approximately $1.6 \mathrm{~m}$ for sites 1-4; see Fig. 3. Sites 1-4 constitute the P2P scenario. Site 5 had an antenna height of approximately $5 \mathrm{~m}$, to emulate a tower-type condition. All antennas were vertically polarized. Computers connected to the spectrum analyzers recorded the received power samples. The receiver noise floor was approximately $114 \mathrm{dBm}$ for the $4860 \mathrm{MHz}$ frequency ${ }^{3}$, allowing a maximum recordable path loss of approximately $145 \mathrm{~dB}$.

The walking path followed by the transmitter team yielded both LOS and NLOS conditions. For each walk at a given frequency, test time was approximately 30-40 minutes. This provided approximately 4000-7000 power samples for each test frequency, at each site. During the test period from approximately 8:30 am to noon, pedestrian and vehicular traffic were moderate. We ensured that no interfering signals were present by sampling the spectra before testing at each frequency. The transmitter-receiver link distances ranged from approximately 10-350 m.

\section{PATH LOSS RESUltS}

Via use of the known transmit powers, cable losses, and antenna gains, propagation path loss from the transmitter to each receiver site was computed from the measured received power. Received power data were separated into LOS and NLOS data, and data for each region were processed separately for path loss.

\section{A. Line-of-Sight Regions}

For each test frequency, we collected all the LOS received power data from two receiver sites, site \#1 and site \#5. These

${ }^{2}$ Note that the transmitter team made small "local" movements for the "stopped" positions, so for the highest frequency where wavelength is approximately $6 \mathrm{~cm}$, small movements on the order of a wavelength occurred naturally, improving the spatial averaging at those points.

${ }^{3}$ For frequencies 430, 750, 905, 1834, and $2400 \mathrm{MHz}$, noise floors are approximately $-109,-103.5,-115,-115$, and $-114 \mathrm{dBm}$, respectively.

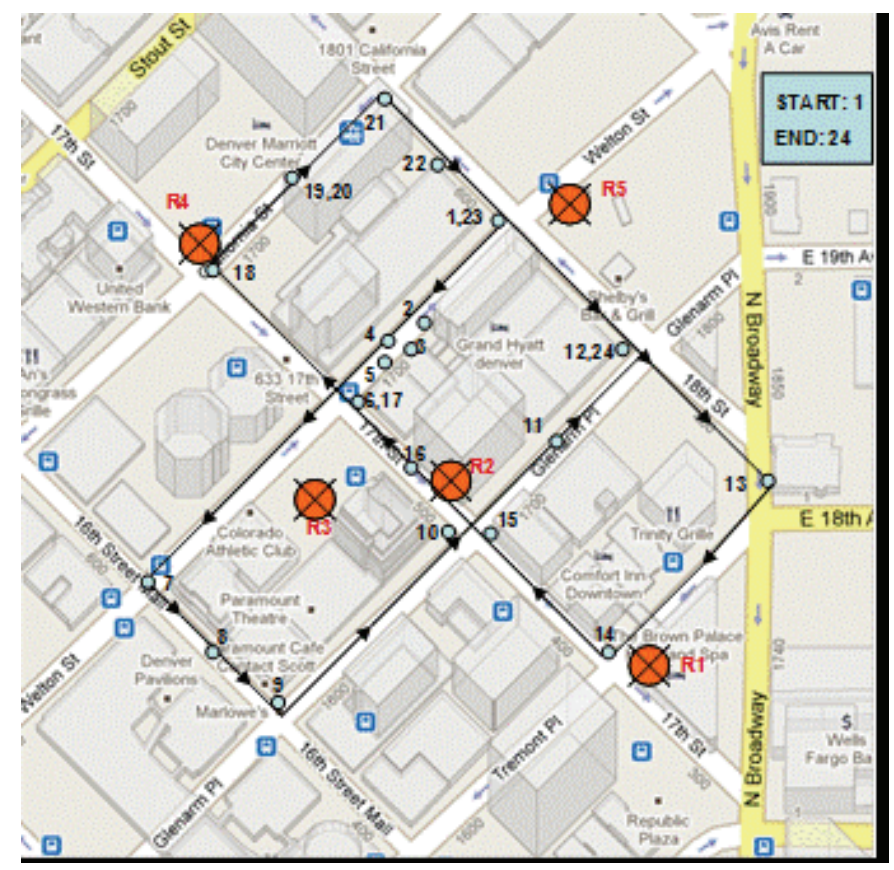

Fig. 1. Google map view of test area in downtown Denver. Transmit path indicated by line with arrows and numbered points from 1 to 24 , and receiver locations indicated by circles, with ith receiver denoted $R i$.

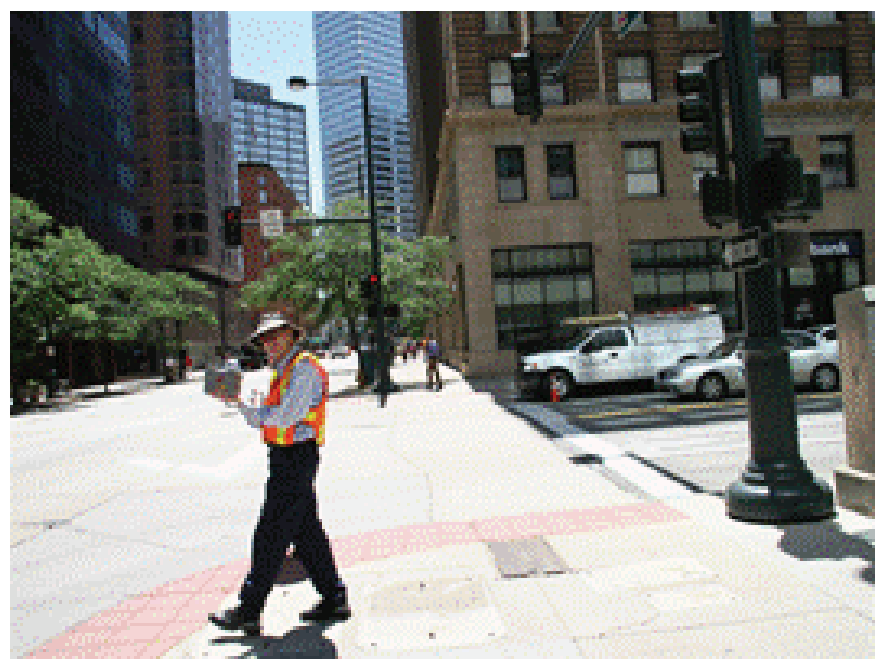

Fig. 2. Pedestrian transmit team at corner of $17^{t h} \&$ Welton Streets.

two sites had some of the longest paths for which a LOS was maintained. For both LOS and NLOS data, we applied a moving average filter of approximately 20 wavelengths $(\lambda)$ (e.g., [16]), and $40 \lambda$ for the two highest frequencies to obtain more points per each distance value. This filters out smallscale fading in the received power samples. From this, we fit measured data using the common log-distance model, with path loss in decibels given by

$$
L(d)=L\left(d_{0}\right)+10 n \log _{10}\left(d / d_{0}\right)+X,
$$

where $n$ is the propagation path loss exponent and $X$ is a zeromean Gaussian random variable with standard deviation $\sigma_{X}$ $\mathrm{dB}$. The constant $L\left(d_{0}\right)$ is the loss at a reference distance $d_{0}$, which determines the line intercept on the log-log scale. The well-known two-ray (or "plane-earth") path loss model [10] is also often used for LOS cases; we omit that formula for 


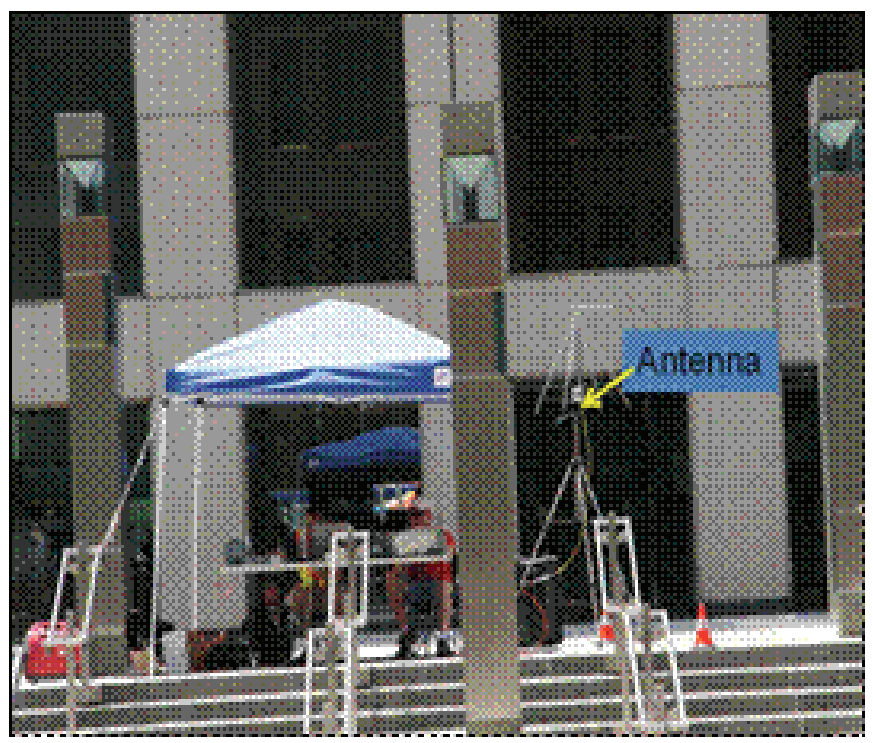

Fig. 3. Site 1 at $17^{\text {th }}$ St. and Tremont Pl.

brevity. In LOS conditions, shadowing does not strictly occur, so the model's random variable $X$ quantifies the deviation from the linear fit; this deviation is most likely due to the presence of reflected components in addition to the LOS and ground reflections. This results in variation in measured data even when the two-ray model is a fairly good one, e.g., [13].

LOS log-distance model path loss exponents $n$ range from 2.4 to 3.5 for the elevated Site 5, and 3.9 to 5.15 for Site 1, with standard deviations from 2.9 to $5.5 \mathrm{~dB}$ and 2.1 to 7.6 $\mathrm{dB}$, respectively. Reference [13] found $n=4$ to hold well for the LOS P2P case; the maximum frequency in [13] was 450 $\mathrm{MHz}$, near our lowest frequency. The two-ray model does not fit the LOS results well for cases when log-distance fits have path loss exponents $n \geq 4$; this occurred primarily for the largest two frequencies (2400 and $4860 \mathrm{MHz}$ ), and is likely due to additional strong reflections from the urban canyon.

\section{B. Non-Line-of-Sight Regions}

For the NLOS path loss results, we did not attempt to model path loss for " $L$-shaped" [13] or " $U$-shaped" [14] paths, since the transmitter paths had multiple turns from any receiver site's perspective. Instead, we computed the "direct" NLOS distance from Tx to Rx; this distance corresponds to a straight line as seen from above, through any obstacles, and is the conventional method of specifying distance, e.g., for cellularsystem path loss models [16]. The moving average filter $(20 \lambda$ or $40 \lambda$ ) was also applied before fitting to the log-distance linear model of (1).

Table I lists the path-loss exponents and Gaussian standard deviations for the log-distance NLOS path losses for all five sites individually, and for data taken collectively for P2P sites 1-4. The aggregate data shows a slight increase of the path loss exponent versus frequency, but aggregate values are all close to $n=4$ : a linear fit to the exponents vs. $\ln$ (frequency) yields the following approximate relation (least-squares fit) $n_{N L O S}(f) \cong 0.28 \ln (f)+1.96$, with $f$ in megahertz. The general increase of path loss with frequency is widely established, e.g., [10], [16], and this particular formula pertains of course to
TABLE I

NLOS PATH-LOSS MODEL PARAMETERS FOR EACH RECEIVER SITE INDIVIDUALLY, AND FOR SITES 1-4 COLLECTIVELY

\begin{tabular}{|c|c|c|c|c|c|c|}
\hline $\begin{array}{l}\text { Frequency } \\
(\mathrm{MHz})\end{array}$ & $n_{N L O S}$ & $\begin{array}{l}s_{X} \\
(\mathrm{~dB})\end{array}$ & $n_{N L O S}$ & $\begin{array}{l}s_{X} \\
(\mathrm{~dB})\end{array}$ & $n_{N L O S}$ & $\begin{array}{l}s_{X} \\
(\mathrm{~dB})\end{array}$ \\
\hline & \multicolumn{2}{|l|}{ Site 1} & \multicolumn{2}{|l|}{ Site 2} & \multicolumn{2}{|l|}{ Site 3} \\
\hline 4860 & 7.12 & 5.88 & 4.41 & 7.32 & 7.27 & 4.99 \\
\hline 2400 & 6.04 & 6.14 & 4.93 & 8.04 & 6.05 & 9.63 \\
\hline 1834 & 6.03 & 5.59 & 4.18 & 5.59 & 5.55 & 8.13 \\
\hline 905 & 4.82 & 5.73 & 4.32 & 6.36 & 6.06 & 8.23 \\
\hline 750 & 4.10 & 4.20 & 4.38 & 5.51 & 5.23 & 8.77 \\
\hline \multirow[t]{2}{*}{430} & 4.66 & 8.20 & 4.23 & 8.04 & 4.32 & 8.91 \\
\hline & \multicolumn{2}{|l|}{ Site 4} & \multicolumn{2}{|l|}{ Site 5} & \multicolumn{2}{|l|}{ Sites 1-4 } \\
\hline 4860 & 5.27 & 9.32 & 4.65 & 4.87 & 4.27 & 9.17 \\
\hline 2400 & 5.26 & 10.27 & 4.15 & 10.3 & 4.43 & 11.24 \\
\hline 1834 & 4.46 & 8.02 & 4.85 & 4.40 & 3.91 & 8.59 \\
\hline 905 & 4.27 & 8.05 & 5.43 & 6.81 & 3.95 & 9.03 \\
\hline 750 & 4.33 & 8.49 & 4.43 & 6.37 & 3.90 & 8.37 \\
\hline 430 & 5.24 & 7.60 & 3.62 & 9.46 & 3.60 & 9.90 \\
\hline
\end{tabular}

our P2P environment and frequency span. The aggregate data exponents are not substantially different from values measured for a cellular setting (with one antenna at substantially larger height) [16]. In contrast, path-loss exponents for individual sites show much greater variation. Discounting the elevated Site 5 data, for the $4860 \mathrm{MHz}$ frequency, we found 4.41 $\leq n_{N L O S} \leq 7.27$; for 2400,1834 , and $905 \mathrm{MHz}, 4.18 \leq$ $n_{N L O S} \leq 6.06$; and for 750 and $430 \mathrm{MHz}, 4.1 \leq n_{N L O S} \leq$ 5.24. Reference [17] found an NLOS exponent of approximately 4.1 at $300 \mathrm{MHz}$, and [18] found analytical (ray-tracing) exponents from 4.6-5.8 at $2 \mathrm{GHz}$ and $5 \mathrm{GHz}$. In [19] the authors reported an urban P2P path loss exponent of 4.9 and shadowing standard deviation of $7.7 \mathrm{~dB}$, at $900 \mathrm{MHz}$. Finally, in [20], P2P measurements in NLOS conditions yielded a path loss exponent of approximately 4, with shadowing standard deviation 6-8 dB, at "UMTS frequencies." Only reference [13] found as large a maximum value of path loss exponent as our measurements revealed; data in [13] are for the path loss in NLOS conditions after turning a corner, and some of the exponents in [13] are even larger than those in Table I.

Figure 4 shows a plot of NLOS path loss vs. logarithm of distance for an example subset of data for three frequencies: 4860, 1834, $430 \mathrm{MHz}$, at sites 1, 3, and 5, respectively. For clarity in illustrating the slopes, neither all data nor all sites are shown. The link distance in Fig. 4 ranges from approximately $50-350 \mathrm{~m}$, and the intercept $L\left(d_{0}=50 \mathrm{~m}\right) \cong 80 \mathrm{~dB}$, the free-space value for $4860 \mathrm{MHz}$. These plots illustrate well the range of path loss exponent variation for the per-site measurements.

\section{CONCLUSION}

We reported on results from simultaneous measurements of received signal power at five spatially-separated sites in an urban environment, for six distinct frequencies in or near public-safety frequency bands, for peer-to-peer conditions and link distances up to $350 \mathrm{~m}$. From the received powers we computed path loss. From these results we created path loss models for both LOS and NLOS conditions. For LOS conditions, a log-distance model with path loss exponents from approximately 4-5 applies, with fit standard deviations from 2-7.6 dB. For the NLOS case, we found path loss exponents to range from approximately 3.6 to 7.3 , and standard deviations 


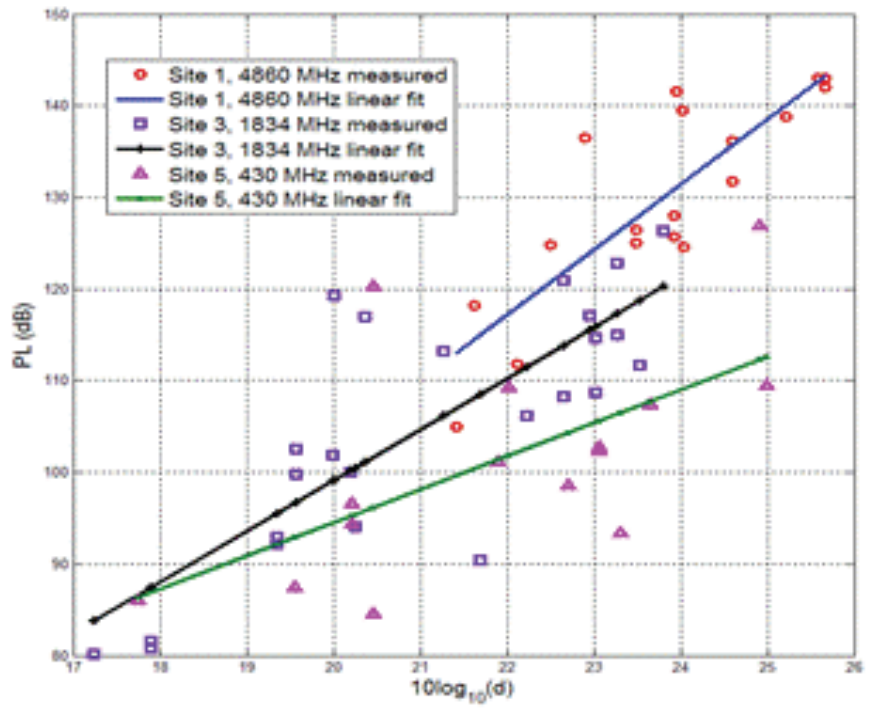

Fig. 4. Example NLOS path loss measured data and log-distance fits for frequencies of 4860,1834 , and $430 \mathrm{MHz}$ at sites 1,3 , and 5, respectively.

4.2-10.3 dB, depending upon site and frequency. For data aggregated from all sites, mean path loss increases with frequency approximately logarithmically.

\section{ACKNOWLEDGMENT}

For their assistance in measurements, the authors thank Kate Remley, Christopher Holloway, William F. Young, Galen Koepke, Jason Coder, and Dennis Camell of the National Institute of Standards and Technology, Boulder, CO.

\section{REFERENCES}

[1] T. L. Doumi, "Spectrum considerations for public safety in the United States," IEEE Commun. Mag., vol. 44, no. 1, pp. 30-37, Jan. 2006.

[2] F. Li and Y. Wang, "Routing in vehicular ad hoc networks: a survey," IEEE Veh. Technol. Mag., vol. 2, no. 2, pp. 12-22, June 2007.

[3] P. Gupta and P. R. Kumar, "The capacity of wireless networks," IEEE Trans. Inf. Theory, vol. 46, pp. 388-404, Mar. 2000.
[4] C. Comaniciu and H. V. Poor, "On energy-efficient cross-layer design: joint power control and routing for ad hoc networks," EURASIP J. Wireless Commun. \& Networking, article ID 60706, volu. 2007.

[5] K. Stamatiou and J. G. Proakis, "Assessing the impact of physical layer techniques on ad hoc network performance," Physical Commun. J., vol. 1, pp. 84-91, 2008.

[6] D. W. Matolak, "Duplexing, multiplexing, and multiple access: a comparative analysis for mesh networks," in Proc. 2008 IEEE MILCOM.

[7] A. Schmitz and M. Wenig, "The effect of the radio wave propagation model in ad hoc networks," in Proc. 2006 ACM Int. Workshop on Modeling, Analysis \& Simulation of Wireless Mobile Systems.

[8] H. Rutagemwa, T. J. Willink, and L. Li, "Modeling and performance analysis of cooperative wireless networks," IEEE Trans. Veh. Technol., vol. 59, no. 6, pp. 3057-3069, July 2010.

[9] H. Sethu and T. Gerety, "A new distributed topology control algorithm for wireless environments with non-uniform path loss and multipath propagation," Ad Hoc Networks, vol. 8, pp. 280-294, 2010.

[10] J. D. Parsons, The Mobile Radio Propagation Channel, 2nd edition. John Wiley \& Sons, 2000.

[11] A. A. M. Saleh abd R. A. Valenzuela, "A statistical model for indoor multipath propagation," IEEE J. Sel. Areas Commun., vol. SAC-5, no. 2, pp. 128-137, Feb. 1987.

[12] D. W. Matolak, "Channel modeling for vehicle-to-vehicle communications," IEEE Commun. Mag., vol. 46, no. 5, pp. 76-83, May 2008.

[13] J. R. Hampton, N. M. Merheb, W. L. Lain, D. E. Paunil, R. M. Shuford, and W. T. Kasch, "Urban propagation measurements for ground based communication in the military UHF band," IEEE Trans. Ant. Prop., vol. 54, no. 2, pp. 644-654, Feb. 2006.

[14] C. Gentile, D. W. Matolak, K. A. Remley, C. L. Holloway, Q. Wu, and Q. Zhang, "Modeling urban peer-to-peer channel multipath characteristics for the $700 \mathrm{MHz}$ and $4.9 \mathrm{GHz}$ public safety bands," in Proc. 2012 IEEE ICC.

[15] Berkeley Varitronics Systems, Inc., website www.bvsystems.com, September 2012.

[16] T. S. Rappaport, Wireless Communications: Principles and Practice, 2nd edition. Prentice Hall, 2002.

[17] G. Eriksson, S. Linder, K. Wiklundh, P. Holm, P. Johansson, F. Tufvesson, and A. Molisch, "Urban peer-to-peer MIMO channel measurements and analysis at $300 \mathrm{MHz}$," Mitsubishi Electric Labs Report TR 2008-076, Dec. 2008.

[18] Z. Wang, E. K. Tameh, and A. R. Nix, "Statistical peer-to-peer channel models for outdoor urban environments at $2 \mathrm{GHz}$ and $5 \mathrm{GHz}$," in Proc. IEEE Veh. Tech. Conf. - Fall.

[19] J. Turkka and M. Renfors, "Path loss measurements for a non-line-ofsight mobile-to-mobile environment," in Proc. 2008 International Conf. on ITS Telecommunications.

[20] K. Konstantinou, S. Kang, and C. Tzaras, "A measurement-based model for mobile-to-mobile UMTS links," in Proc. 2007 Spring Vehicular Tech. Conf. 